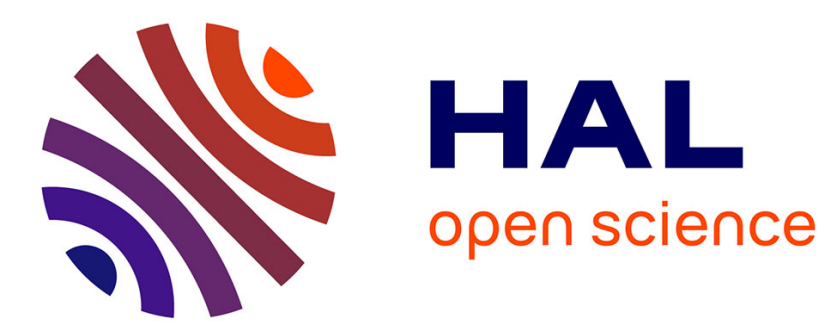

\title{
Activating and Inhibitory Receptors on Mast Cells
}

Anna Niarakis, Marc Daëron

\section{To cite this version:}

Anna Niarakis, Marc Daëron. Activating and Inhibitory Receptors on Mast Cells. Encyclopedia of Medical Immunology, Springer New York, pp.1-10, 2014, 10.1007/978-1-4614-9194-1_92 . hal03192429

\section{HAL Id: hal-03192429 \\ https://hal.science/hal-03192429}

Submitted on 8 Apr 2021

HAL is a multi-disciplinary open access archive for the deposit and dissemination of scientific research documents, whether they are published or not. The documents may come from teaching and research institutions in France or abroad, or from public or private research centers.
L'archive ouverte pluridisciplinaire HAL, est destinée au dépôt et à la diffusion de documents scientifiques de niveau recherche, publiés ou non, émanant des établissements d'enseignement et de recherche français ou étrangers, des laboratoires publics ou privés. 


\section{Activating and Inhibitory Receptors on Mast Cells Anna Niarakis ${ }^{1}$ and Marc Daëron ${ }^{2,3^{*}}$}

${ }^{1}$ Ecole Normale Supérieure, Institut de Biologie, UMR ENS-CNRS 8197-Inserm U.1024, Paris, 2Institut Pasteur, Centre d'Immunologie Humaine, Département d'Immunologie, Paris, ${ }^{3}$ Centre d'Immunologie de Marseille Luminy, Inserm U.1104-CNRS UMR 7280, Marseille

*Corresponding author:

Marc Daëron, MD, PhD, Département d'Immunologie, Bâtiment Metchnikoff, Institut Pasteur, 25 rue du Docteur Roux, 75015 Paris, France.

e-mail: daeron@pasteur.fr

\section{Synonyms (Keywords)}

Mast cells, Cell activation, Regulation, Cell signaling, Allergy, Inflammation 


\section{Definition}

Cell activation results from the transient displacement of a balance of positive and negative signals that are constitutively generated in resting cells. This physiological balance can be displaced when cell surface receptors are engaged by extracellular ligands. Mast cells express a variety of membrane receptors that control the biological responses of these cells. These include activating receptors and inhibitory receptors.

Activating receptors positively regulate biological responses of mast cells. Receptors for the $\mathrm{Fc}$ portion of immunoglobulins $(\mathrm{FcR})$ such as high-affinity IgE receptors (Fc\&RI) trigger an array of secretory responses including the exocytosis of preformed mediators, the generation of arachidonic acid-derived eicosanoids and the secretion of cytokines, chemokines and growth factors. FceRI do not trigger proliferative signals. Conversely, cytokine or growth factor receptors, such as Interleukin-3 receptors (IL-3R) or the Stem Cell Factor (SCF) receptor Kit, induce mast cell proliferation. They trigger no or minimal activation signals. Inhibitory receptors negatively regulate biological responses induced by activating receptors.

\section{Activating and inhibitory receptors}

Activating and inhibitory receptors trigger signals when they are engaged by specific extracellular ligands. Except G Protein-Coupled Receptors (GPCR) that can trigger signals when binding monovalent ligands, most receptors trigger signals when aggregated by plurivalent ligands. Ligands with several identical binding sites or made of complexes of several identical molecules, aggregate identical receptors on the same cell. This homoaggregation applies to most activating receptors. Thus, FceRI are aggregated when a multivalent antigen binds to receptor-bound IgE. Because mast cells co-express several receptors and because many extracellular ligands consist of complexes of different molecules, different receptors may be co-engaged by a single ligand. This heteroaggregation may apply to different activating receptors or to activating and inhibitory receptors. In the first case positive signals generated by activating receptors can synergize. In the second case, negative signals generated by inhibitory receptors antagonize with positive signals generated by activating receptors.

Activating receptors generate not only activation signals, but also inhibition signals. This can be unraveled by monitoring the release of granular mediators by mast cells sensitized with a constant amount of IgE antibodies and challenged with increasing concentrations of specific antigen. Mediator release dose-dependently increases up to an optimal concentration of antigen. Beyond this concentration, mediator release declines progressively and, in large excess of antigen, it is abrogated. This long-known bell-shaped dose-response curve was recently demonstrated to result from an active auto-inhibition of activating receptor signaling that limits mast cell activation beyond a given threshold (Huber, 2013).

Inhibitory receptors generate inhibition signals only. They however need to cooperate with activating receptors in order to inhibit mast cell activation. Such cooperation is possible when extracellular ligands co-engage the two types of receptors on the same cell. IgG immune complexes, which can bind to FceRI-bound IgE antibodies via the antigen moiety and to the inhibitory low-affinity IgG receptors Fc $\gamma$ RIIB via the Fc portions of IgG antibodies, are such ligands. Activating and inhibitory receptors that are co-expressed by mast cells may have different specificities, such as FceRI and FcyRIIB. Others, such as PIR-A and PIR-B, have the same specificity. They present themselves as pairs of activating and inhibitory receptors that are co-engaged by the same ligands. 


\section{Signaling mechanisms used by activating receptors}

\section{Signal transduction by activating receptors.}

Signal transduction is the transformation of a mechanical perturbation, generated at the extracellular side of the plasma membrane, into a chemical perturbation, generated at the intracellular side of the membrane. The extracellular mechanical perturbation can consist in a conformational change or in the formation of receptor aggregates. The degree of aggregation depends on receptors and ligands. Kit or IL-3R is dimerized by SCF or IL-3, respectively. FceRI are generally aggregated by multivalent antigens when these bind to receptor-bound IgE. In the vast majority of cases, the intracellular chemical perturbation is a phosphorylation event that is made possible because receptor aggregation brings close to each other protein kinases and their substrates. The kinases and their substrates depend on the type of receptors involved.

Growth factor receptors such as Kit are themselves tyrosine kinases, hence their generic name Receptor Tyrosine Kinases (RTK). Their intracytoplasmic domain contains both the enzyme, i.e. a tyrosine kinase catalytic domain, and its substrates i.e. multiple tyrosines that become phosphorylated by a trans-phosphorylation process when RTK are dimerized by growth factors (Lemmon and Schlessinger, 2010).

Activating FcR contain Immunoreceptor Tyrosine-based Activation Motifs (ITAM) that are phosphorylated by src-family tyrosine kinases. These enzymes are especially abundant in sphingolipid/cholesterol-rich membrane microdomains into which engaged receptors transiently translocate. When phosphorylated, ITAM recruit molecules that possess Src Homology 2 (SH2) domain(s). SH2 domains have an affinity for specific tyrosylphosphorylated molecules, among which are cytosolic tyrosines kinases and adapter molecules (Siraganian, 2003).

Other activating receptors, such as the SLAM family member 2B4, contain several Immunoreceptor Tyrosine-based Switch Motifs (ITSM), which, when phosphorylated, recruit SAP, an adapter molecule consisting of one SH2 domain (Veillette, 2010).

The engagement of Toll-like receptors (TLR) enables the recruitment of adapter molecules, such as Myd88 and/or TRIF, which recruit the protein kinases IRAK and TBK1, respectively (Sandig and Bulfone-Paus, 2012).

The engagement of cytokine receptors triggers the phosphorylation of transcription factors of the Signal Transducer and Activator of Transcription (STAT) family by Janus kinases (Jak) that are activated upon cytokine binding (Ihle et al., 1995).

Ligand binding triggers conformational changes of the heterotrimeric G Protein-coupled Receptors. This enables guanoside diphosphate (GDP), with which inactive receptors are associated, to be exchanged for guanosine trisphosphate (GTP) with which activated receptors are associated. Further signal transduction depends on the type of G protein (Hur and Kim, 2002).

Glycosylphosphatidylinositol (GPI)-anchored receptors have no intracytoplasmic domain. They, however, concur to cell signaling by trapping activating receptors in src kinase-rich lipid microdomains where they reside, or by engaging activating receptors through interactions with their extracellular domains (Suzuki et al., 2007). 
Generation of signalosomes and intracellular propagation of activation signals.

Whatever the receptors and the mechanisms by which initial signals were transduced, proximal signaling events enable the constitution of intracellular signalosomes that build up on scaffold proteins and in which signaling molecules are spatiotemporally organized. Molecules that are recruited and activated in signalosomes launch metabolic pathways, which ensure the intracellular propagation of signals from the membrane to the nucleus.

These pathways lead to the generation of phopshatidylinositol 3,4,5-trisphosphate $[\mathrm{PI}(3,4,5) \mathrm{P} 3]$ by phosphatidylinositol 3-kinase (PI3K) and the subsequent membrane translocation of signaling molecules that have a Plextrin Homology domain, to the activation of various types of Protein Kinases (PKA, PKC...) and the subsequent activation of factors which, like NF- $\kappa \mathrm{B}$, control transcription, to the activation of small GTPases of the Ras, Rac and Rho families and the subsequent activation of Mitogen-Activated Protein (MAP) kinases, to an increased concentration of intracellular $\mathrm{Ca}^{2+}$ and the subsequent activation of $\mathrm{Ca}^{2+}$-dependent enzymes. Ultimately, these pathways end by the nuclear translocation of a variety of transcription factors and the subsequent transcription of cytokine genes.

Most intracellular pathways that lead to gene transcription are shared by the various activating receptors. The nature of biological responses of the cell depends on combinations of transcriptional events that control the expression of genes that encode secretory products or molecules, such as cyclins, that control the cell cycle and, ultimately, cell proliferation. As a consequence, pathways that are activated simultaneously by different receptors can merge and/or interfere with each others. The integration of signals generated by different activation receptors generally leads to an amplification of activation signals whereas the integration of signals generated by activating and inhibitory receptors leads to the negative regulation of activation signals (Bezbradica and Medzhitov, 2012).

\section{Signaling mechanisms used by inhibitory receptors}

\section{ITIM-containing inhibitory receptors}

The vast majority of inhibitory receptors contain one or several Immunoreceptor Tyrosinebased Inhibition Motifs (ITIM) (Daëron et al., 2008). A hallmark of ITIM-containing molecules is that they become tyrosyl-phopshorylated, which enables them to recruit SH2 domain-containing phosphatases that inhibit cell activation. SH2 domain-containing phosphatases are indeed the intracellular effectors of negative signaling by ITIMcontaining receptors. Depending on the receptor and on the phosphatase, the mechanisms of ITIM phosphorylation, the mechanism of phosphatase recruitment and the consequences of this recruitment differ.

Four SH2 domain-containing phosphatases have been identified: the two lipid phosphatases SHIP1 and SHIP2 and the two tyrosine phosphatases SHP-1 and SHP-2. ITIMcontaining receptors recruit either SHIP1/2 or SHP-1/2. Both types of inhibitory receptors require to be co-engaged with activating receptors to inhibit, but for different reasons: coaggregation brings tyrosine kinases close to their substrates in the first case, whereas it brings tyrosine phosphatases close to their substrates in the second case.

Fc $\gamma$ RIIB is the only bona fide ITIM-containing receptor that recruits SHIP1/2. These phosphatidylinositol 5-phosphatases have indeed an affinity for the phosphorylated Fc $\gamma$ RIIB ITIM, but not for those of most other ITIM-containing inhibitory receptors. Also, Fc $\gamma$ RIIB, which have a single ITIM, cannot recruit the two-SH2 domain-containing SHP-1/2. 
Fc $\gamma$ RIIB aggregation does not lead to ITIM phosphorylation. The coaggregation of Fc $\gamma$ RIIB with activating receptors does. Coaggregation indeed enables Src kinases that associate with activating receptors to phosphorylate also the ITIM in the inhibitory receptor. As a consequence, Fc $\gamma$ RIIB-dependent negative regulation does not operate in resting cells. It only operates when activation has been launched. Once recruited by phosphorylated, Fc $\gamma$ RIIB, SHIP1 can inhibit activation signals by at least two mechanisms. One depends on its enzymatic activity; the other does not. SHIP1 hydrolyzes the 5-phosphate group in the inositol ring of PI(3,4,5)P3, preventing thus PI(3,4,5)P3-dependent recruitment of critical signaling molecules. When phosphorylated, SHIP1 recruits a cytosolic adapter that recruits rasGAP, which inhibits Ras activation and, ultimately, prevents the transcription of cytokine genes.

Other ITIM-containing receptors, i.e. most inhibitory receptors have more than one ITIM and they use the two-SH2 domain-containing tyrosine phosphatases to inhibit cell activation. Unlike Fc $\gamma$ RIIB, these receptors are constitutively associated with Src family tyrosines kinases. Their phosphorylation therefore requires that they are aggregated, but not that they are co-aggregated with activating receptors. When tyrosyl-phosphorylated, they recruit SHP-1/2, but not SHIP1/2. Coaggregation is necessary for these molecules to inhibit cell activation. Indeed, SHP-1/2 need to be brought close to their phosphorylated substrates for being able to act on them. The substrates of SHP-1 and/or SHP-2 include molecules that are present in the signalosome and whose phosphorylation is critical for both proximal and distal activation signals.

\section{Inhibitory receptors that do not contain ITIM}

Some receptors can use ITIM-independent mechanisms to negatively regulate mast cell activation. One of the ITSM of 2B4 can recruit various molecules involved in negative signaling. The OX-2 glycoprotein receptor CD200R contains no ITIM but a tyrosine-rich region which, upon phosphorylation can recruit SHIP1 via the recruitment of Dok1/2. G Protein-coupled receptors that activate adenylate cyclase, such as the adenosine receptors $\mathrm{A} 2 \mathrm{a}$ and $\mathrm{A} 2 \mathrm{~b}$ and the PGE2 receptor EP2, can inhibit mast cell activation by increasing the intracellular levels of cyclic AMP. When engaged by the filarial protein ES-62, TLR-4 sequesters Protein Kinase $\mathrm{C} \alpha$ and inhibits FceRI signaling. Transforming Growth Factor $\beta$ down-regulates FceRI expression by inhibiting the synthesis of FceRI $\alpha, F c R \gamma$ and FcR $\beta$ at the translational level. The member of the TIR domain-containing superfamily of TLR family and IL-1 receptors, IL-33 receptor (aka ST2) inhibits IL-4R signaling by interacting with the adapters MyD88 and Mal.

\section{Activating and inhibitory receptors expressed by mast cells}

\section{Activating receptors}

Activating receptors expressed by mast cells are listed in Table 1 (Migalovich-Sheikhet et al., 2012, Gilfillan and Tkaczyk, 2006). They belong to several families of receptors: the Immunoglobulin Superfamily (IgSF), the GPCR family, Cytokine receptors, TLR and GPIlinked receptors.

IgSF receptors comprise RTK that possess themselves a tyrosine kinase domain and ITAMor ITSM-containing receptors that recruit tyrosine kinases. Mast cell RTK include receptors for growth factors such as SCF and Vascular-Endothelial Growth Factor. They promote mast cell proliferation. ITAM-containing receptors expressed by mast cells are receptors 
for the Fc portion of antibodies. They include the high-affinity IgE receptors FceRI and the low-affinity IgG receptors Fc $\gamma$ RIIA in humans and Fc $\gamma$ RIIIA in mice. The high-affinity IgG receptors $\mathrm{Fc} \gamma \mathrm{RI}$ can be induced by IFN- $\gamma$ in human but not in mouse mast cells. Whatever their specificity, these FcR trigger mast cell activation when engaged by antibodies and antigen. ITSM-containing receptors are the SLAM family member 2B4 that can be engaged either by 2B4 through homotypic aggregation, or by other SLAM family members through heterotypic aggregation, on the same or on different membranes.

A heterogeneous group of GPCR comprise receptors for chemokines, lipid mediators, vasoactive amines, sphingosine phosphate, adenosine, neuropeptides and anaphylatoxins. Most of these receptors can induce mast cell secretion. Some, like leukotriene receptors, induce mast cell proliferation. Others, like chemokine receptors, trigger mast cell chemotaxis. They thus mediate the recruitment of mast cells in inflammatory sites. Endothelins are a family of vasoactive peptides that can both be produced by mast cells and activate mast cells through the endothelin receptors $\mathrm{ET}_{\mathrm{A}}$. Mast cells, however, also produce proteases that degrade endothelin.

Mast cell cytokine receptors include IL-3R, IL-4R, IL-5R and TSLP/IL-7R. They trigger mast cell differentiation and proliferation. Toll-like receptors such as TLR-2 and TLR-4 induce mast cell to secrete cytokines but not to degranulate when engaged by endotoxins or other bacterial products.

Several GPI-anchored receptors have been reported to trigger mast cell responses. Thus, the urokinase-type plasminogen activator receptor (UPAR, CD87) induces human mast cell chemotaxis. Various bacteria bind to CD48 and trigger phagocytosis and cytokine secretion. CD48 can also be engaged by 2B4, a member of the SLAM family that is co-expressed by mast cells, and trigger cell activation.

Activating receptors can also generate negative signals that inhibit mast cell activation. FceRI signaling is regulated by SHIP1 in the absence of inhibitory receptor engagement (Huber, 2013). IgE-induced secretory responses are markedly enhanced in SHIP1\% mast cells, and SHIP1 is dose-dependently tyrosyl-phosphorylated when FceRI-bound IgE are engaged by increasing concentrations of antigen in wild-type mast cells. The mechanism by which FceRI recruits SHIP1 in this auto-regulation is unclear. Likewise, 2B4 can activate mast cells when engaged by members of the CD2 family such as CD48. 2B4, however, also generates inhibitory signals. 2B4 indeed contains four ITSM, three of which recruit molecules that concur to cell activation whereas one of them recruits SHP-1/2, SHIP1 and Csk that inhibit cell activation (Veillette, 2010).

\section{Inhibitory receptors}

Inhibitory receptors expressed by mast cells are listed in Table 2 (Migalovich-Sheikhet et al., 2012). Three groups of receptors can be distinguished: ITIM-containing inhibitory receptors that use the lipid phosphatases SHIP1/2, ITIM-containing inhibitory receptor that use the protein phosphatases SHP-1/2 and inhibitory receptors that have no ITIM (Daëron et al., 2008).

Fc $\gamma$ RIIB are the only ITIM-containing receptors that recruit SHIP1/2. The co-engagement of Fc $\gamma$ RIIB with FceRI or with Fc $\gamma$ RIIIA by antigen-antibody complexes on mouse mast cells dramatically inhibits all IgE- or IgG-induced responses (Daëron et al., 1995). The coengagement of Fc $\gamma$ RIIB with Kit inhibits SCF-induced mouse mast cell proliferation (Malbec et al., 1999). Although high amounts of Fc $\gamma$ RIIB that have a major dominant inhibitory effect on IgG- and IgE-induced activation were found in human basophils, Fc $\gamma$ RIIB 
expression is questionable on human mast cells. It may differ markedly on mast cells from different tissues. Human cord blood-derived mast cells were indeed reported to express Fc $\gamma$ RIIB, but not skin-derived human mast cells.

The co-engagement of FceRI with all other ITIM-containing receptors also inhibits mast cell activation. These inhibitory receptors include Siglec, which binds to sialic acid, SIRP $\alpha$, which binds to the widely express CD47, the MCH class I receptors PIR-B, ILT/LIR and NKG2A, PECAM-1 which aggregates with itself, LAIR-1, which bind to collagen, CD72, which binds to CD5, gp49B1 that binds to integrins, CD300/MAIR that binds to phosphatidyl serine, phosphatidyl ethanolamine and ceramides on dead cells, and Allergin-1, whose ligands are unknown. All these receptors contain more than one ITIM. This enables them to recruit the two-SH2 domain-containing tyrosine phosphatases SHP-1 and/or 2.

Inhibitory receptors with no ITIM include receptors for cytokines, such as the IL-10R and the IL-33 receptor ST2, the transforming growth factor TGF $\beta$ receptor1, the adenosine receptors $\mathrm{A} 2 \mathrm{a}$ and $\mathrm{A} 2 \mathrm{~b}$, the prostaglandin $\mathrm{E} 2$ receptor $\mathrm{EP} 2, \mathrm{CD} 200 \mathrm{R}$ that binds to the glycoprotein OX-2 (CD200), expressed by a broad range of tissues including lymphoid cells, neurons and endothelium, and TLR-4, which inhibits FceRI signaling when engaged by the filarial protein ES-62.

\section{Mast cell receptors in health and disease}

Inflammation is a physiological defense mechanism. It involves the many myeloid cells that function as the cellular effectors of innate and adaptive immune responses. Mast cells are among these cells. These can be activated by microbial products and by a variety of other molecules in innate immunity or by molecular effectors of adaptive immunity via cytokine, chemokine and Fc receptors (Newton and Dixit, 2012). Normally, inflammation is tightly controlled and remains unapparent. It can be pathogenic if it escapes from regulation. Autoimmunity and allergy are examples of pathological inflammation generated by not properly controlled immune responses. Mast cells have been implicated in both conditions. A well-controlled balance between activating and inhibitory receptors therefore determines whether mast cells contribute to protective immunity or to pathogenic immunity (Gilfillan and Beaven, 2011). Human mast cells, however, were involved in various pathological processes (Bischoff, 2007).

\section{Mast cell receptors in protective processes}

Although they are mostly known for their pathogenic properties, mast cells have been increasingly recognized to have protective roles. Several mast cell TLR are involved in the protection against microorganisms, as mast cell-deficient mice were markedly more sensitive to infection by several pathogens, especially Gram-negative bacteria. This protection primarily depends on TLR-induced TNF- $\alpha$ secretion. Interestingly, nematodes that express ES62, a protein produced by parasitic roundworms, were reported to modulate mast cell-dependent inflammation. Mast cells were found to protect from honeybee, snake, lizard and scorpion venoms. Venoms indeed induce mast cell degranulation via the endothelin receptor $\mathrm{ET}_{\mathrm{A}}$ and they are degraded by proteases contained in granules released by activated mast cells. Urokinase can protect from bronchial obstruction by promoting fibrinolysis through mast cell urokinase-type plasminogen activator receptors. As they bind to lipids expressed by the membrane of dead cells, CD300/MAIR have been proposed to contribute to the removal of apoptotic cells. 
Activating receptors expressed by mast cells have been involved in pathological mast cell proliferations, chronic inflammation, anaphylaxis, allergy (Galli and Tsai, 2012) and autoimmunity.

Kit is essential for mast cell proliferation and differentiation, particularly into serosal-type mast cells. Gain-of-function mutations of Kit are responsible for the uncontrolled proliferation of mast cells in mastocytosis and mastocytomas (Gotlib et al., 2013).

Inflammation involves the attraction of numerous cells at inflammatory sites. Altogether, chemokine receptors attract mast cells by stimulating chemotaxis in response to a variety of chemoattractants. By acting on mast cell purinergic receptors, adenosine present in extracellular fluid contributes to asthma symptoms. Adenosine indeed provokes a mastcell-dependent broncoconstriction in asthmatic and chronic obstructive pulmonary disease patients (Rudich et al., 2012). Corticotropin-releasing hormone receptors are thought to account for stress-induced inflammation and stress-enhanced allergic reactions. The engagement of neuropeptide receptors by substance $P$ activates human skin mast cells and are involved in the pathogenesis of urticaria (Nakamura et al., 2009).

Anaphylaxis is a hyperacute systemic allergic reaction. IgE-induced, FceRI-dependent mast cell activation accounts for IgE-induced passive anaphylaxis, and it is well known to initiate allergic reactions. IgG antibodies, however, are also potent inducers of anaphylaxis (Jonsson and Daëron, 2012). Both types of reaction are dampened by Fc $\gamma$ RIIB. Likewise, gp49B1 protects from anaphylaxis. gp49B1-deficient mice indeed exhibited enhanced IgEinduced anaphylactic shocks. The recently described ITIM-containing receptors of the CD300 family were found to act as potent negative regulators of anaphylaxis and of other FceRI-dependent allergic reactions (Borrego, 2013). By enhancing IgE-induced mast cell activation, Platelet-Activating Factor (PAF) can aggravate allergic reactions. By activating airway mast cells directly, it can contribute to bronchospasm in anaphylaxis. PAF plasma levels are increased in patients undergoing anaphylaxis. The anaphylatoxins C3a and C5a are generated during anaphylaxis and the level of C3a correlates with the severity of the shock. C5a, but not C3a, behaves as a skin mast cell secretagogue in humans (Schafer et al., 2013). Sphingosine receptors are likely to be involved in anaphylaxis as their blockade reduced circulating histamine levels in mast cell-dependent mouse anaphylaxis. Serotonin receptors expressed by human mast cells were involved in allergic contact eczema, atopic eczema and psoriasis. Finally, histamine can activate mast cells via H4-R and induce leukeutriene B4 secretion. Mast cells, however, also express H2-R through which histamine can inhibit mast cell activation. The interplay between these two receptors can therefore control the effects of histamine on mast cells.

Mast cells have been involved in several systemic autoimmune diseases that depend on autoantibodies (Sayed et al., 2008). The engagement of IgG receptors that have antagonistic properties, may critically determine the clinical outcome. Thus, the reconstitution of mast cell-deficient mice with mast cells from mice lacking activating $F c \gamma R$ failed to restore experimental encephalomyelitis, while reconstitution by mast cells from Fc $\gamma$ RIIB-deficient mice enhanced the disease.

\section{Mast cell receptors in therapeutics}

The many pathological processes in which mast cell receptors are involved make them potential targets/tools in therapeutics for a variety of diseases. Conceivably, one can aim at dampening activation signals whose excess causes mast cell-dependent pathological effects and/or at enhancing inhibition signals that insufficiently control mast cell 
activation. Conversely, one can aim at enhancing activation signals involved in mast celldependent protective processes and/or at dampening inhibitory signals. One can therefore imagine all kinds of theoretical interventions that could have beneficial effects in disease. Below are mentioned only examples of therapeutic approaches that have been used in the clinics or, at least, the proof of concept of which has been demonstrated in animal models. These treatments comprise chemical inhibitors of receptor signaling, natural ligands of mast cell receptors, antibodies against receptors, whether used as antagonists or as agonists, antibodies against receptor ligands, and bi-specific molecules that co-engage different receptors. Symptomatic treatments that aim at inhibiting the pharmacological effects of mast cell mediators by targeting corresponding receptors on other cell types are not considered here.

As it is caused by an uncontrolled Kit activation, clinical trials based on the use of tyrosine kinase inhibitors have been conducted in mastocytosis patients. Globally, the results have not met expectations. Possible reasons are that multiple Kit mutations have been found in mastocytosis, all of which may not be sensitive to inhibitors. A small molecule that inhibits Syk was found to inhibit IgE-induced mouse mast cell activation in vitro and, when administered orally, experimental anaphylaxis in vivo. Allergen-driven symptoms were reduced in allergic rhinitic patients exposed to pollen following intranasal dosing of a Syk inhibitor. Antihistamine receptors have long been used in allergy. Although they probably also act on mast cell receptors, their therapeutic effect likely depends more on their action on histamine receptors expressed by the many cells involved in allergic inflammation.

An example of the use of natural ligands of mast cell receptors in therapeutics is the thrombolytic effects of low-doses of urokinase that has been proposed to treat patients with massive pulmonary emboli. Here again, the action of the drug on mast cells is likely to be a minor contribution to the therapeutic effect.

The best example of an efficient therapeutic antibody that targets a ligand of mast cell receptors is anti-IgE. This humanized monoclonal anti-human IgE is directed against an epitope located in the binding site of IgE that interacts with FceRI. It was conceived as a mean to prevent the binding of antibodies to IgE receptors on mast cells. It turned out to act differently. It was indeed found to remove most of plasma IgE, leading to a dramatic downregulation of FceRI expressed by mast cells and other cells. Receptor occupancy by IgE indeed markedly increases the FceRI half-life on the cell membranes. Consequently, in the absence of IgE, unoccupied FceRI are rapidly degraded and they are virtually removed from the surface of mast cells and basophils. More than 10 years of use proved anti-IgE antibodies to be an efficient treatment of several allergic conditions associated with low to moderately elevated IgE levels.

Antibodies can be used as agonists rather than as blockers. Thus, antibodies directed against the inhibitory receptor CD200R before antigen challenge were reported to inhibit experimental Passive Cutaneous Anaphylaxis in mice and macaques.

Finally, attempts have been made to use bispecific molecules that co-engage FceRI with inhibitory receptors. Three types of molecules have been used to co-engage FceRI with Fc $\gamma$ RIIB. One was a genetically engineered fusion molecule made of the $\mathrm{C}$-terminal domains of a human IgE and the C-terminal domains of a human IgG1. Another was a fusion protein made of a major cat allergen and the C-terminal domain of a human IgG1. A third molecule was made by chemically coupling a Fab fragment from an anti-IgE antibody directed against an epitope outside of the binding site to FceRI (hence accessible on FceRI-bound IgE) and a Fab fragment of an anti-human Fc $\gamma$ RII. Proof of concept validation was obtained for the three molecules in experimental models. A similar approach was attempted that aimed at co-engaging FceRI with CD300/MAIR. A bispecific antibody fragment linking 
CD300a to FceRI-bound IgE abolished IgE dependent PCA and antigen-induced acute experimental asthma. Interestingly, bispecific antibody fragments that crosslinked CD300a with Kit or with CCR3 abrogated mast cell-dependent inflammatory processes, in vitro and in vivo.

\section{Conclusion}

Present throughout the body, mast cells are involved in a variety of processes. Although mast cell-dependent pathogenic processes are better known, mast cell-dependent protective processes are increasingly recognized. Noticeably, mast cells are among the few cells whose activation can lead to death within minutes. Under physiological conditions, however, mast cell activation remains unapparent. All things considered, it therefore makes sense that mast cell activation be tightly controlled. The many receptors expressed by mast cells that trigger positive and negative signals can account for this control. As a consequence, either a failure of receptors to fulfill their task or an excess of their activity, may affect the balance that keeps mast cell activation within the limits of physiology. A better knowledge of mast cell receptors and of their functioning is essential to unravel the etiology of inflammatory diseases such as allergy and to devise new therapeutic tools that will hopefully treat causes rather than symptoms. 


\section{References}

BEZBRADICA, J. S. \& MEDZHITOV, R. 2012. Role of ITAM signaling module in signal integration. Curr Opin Immunol, 24, 58-66.

BISCHOFF, S. C. 2007. Role of mast cells in allergic and non-allergic immune responses: comparison of human and murine data. Nat Rev Immunol, 7, 93-104.

BORREGO, F. 2013. The CD300 molecules: an emerging family of regulators of the immune system. Blood.

DAËRON, M., JAEGER, S., DU PASQUIER, L. \& VIVIER, E. 2008. Immunoreceptor tyrosine-based inhibition motifs: a quest in the past and future. Immunol Rev, 224, 11-43.

DAËRON, M., MALBEC, O., LATOUR, S., AROCK, M. \& FRIDMAN, W. H. 1995. Regulation of highaffinity IgE receptor-mediated mast cell activation by murine low-affinity IgG receptors. J Clin Invest, 95, 577-85.

GALLI, S. J. \& TSAI, M. 2012. IgE and mast cells in allergic disease. Nat Med, 18, 693-704.

GILFILLAN, A. M. \& BEAVEN, M. A. 2011. Regulation of mast cell responses in health and disease. Crit Rev Immunol, 31, 475-529.

GILFILLAN, A. M. \& TKACZYK, C. 2006. Integrated signalling pathways for mast-cell activation. Nat Rev Immunol, 6, 218-30.

GOTLIB, J., PARDANANI, A., AKIN, C., REITER, A., GEORGE, T., HERMINE, O., KLUIN-NELEMANS, H., HARTMANN, K., SPERR, W. R., BROCKOW, K., SCHWARTZ, L. B., ORFAO, A., DEANGELO, D. J., AROCK, M., SOTLAR, K., HORNY, H. P., METCALFE, D. D., ESCRIBANO, L., VERSTOVSEK, S., TEFFERI, A. \& VALENT, P. 2013. International Working Group-Myeloproliferative Neoplasms Research and Treatment (IWG-MRT) \& European Competence Network on Mastocytosis (ECNM) consensus response criteria in advanced systemic mastocytosis. Blood.

HUBER, M. 2013. Activation/Inhibition of mast cells by supra-optimal antigen concentrations. Cell Commun Signal, 11, 7.

HUR, E. M. \& KIM, K. T. 2002. G protein-coupled receptor signalling and cross-talk: achieving rapidity and specificity. Cell Signal, 14, 397-405.

IHLE, J. N., WITTHUHN, B. A., QUELLE, F. W., YAMAMOTO, K. \& SILVENNOINEN, O. 1995. Signaling through the hematopoietic cytokine receptors. Annu Rev Immunol, 13, 369-98.

JONSSON, F. \& DAËRON, M. 2012. Mast cells and company. Front Immunol, 3, 16.

LEMMON, M. A. \& SCHLESSINGER, J. 2010. Cell signaling by receptor tyrosine kinases. Cell, 141, 1117-34.

MALBEC, O., FRIDMAN, W. H. \& DAËRON, M. 1999. Negative regulation of c-kit-mediated cell proliferation by Fc gamma RIIB. J Immunol, 162, 4424-9.

MIGALOVICH-SHEIKHET, H., FRIEDMAN, S., MANKUTA, D. \& LEVI-SCHAFFER, F. 2012. Novel identified receptors on mast cells. Front Immunol, 3, 238.

NAKAMURA, Y., KAMBE, N., SAITO, M., NISHIKOMORI, R., KIM, Y. G., MURAKAMI, M., NUNEZ, G. \& MATSUE, H. 2009. Mast cells mediate neutrophil recruitment and vascular leakage through the NLRP3 inflammasome in histamine-independent urticaria. J Exp Med, 206, 1037-46.

NEWTON, K. \& DIXIT, V. M. 2012. Signaling in innate immunity and inflammation. Cold Spring Harb Perspect Biol, 4.

RUDICH, N., RAVID, K. \& SAGI-EISENBERG, R. 2012. Mast cell adenosine receptors function: a focus on the a3 adenosine receptor and inflammation. Front Immunol, 3, 134.

SANDIG, H. \& BULFONE-PAUS, S. 2012. TLR signaling in mast cells: common and unique features. Front Immunol, 3, 185. 
SAYED, B. A., CHRISTY, A., QUIRION, M. R. \& BROWN, M. A. 2008. The master switch: the role of mast cells in autoimmunity and tolerance. Annu Rev Immunol, 26, 705-39.

SCHAFER, B., PILIPONSKY, A. M., OKA, T., SONG, C. H., GERARD, N. P., GERARD, C., TSAI, M., KALESNIKOFF, J. \& GALLI, S. J. 2013. Mast cell anaphylatoxin receptor expression can enhance IgEdependent skin inflammation in mice. J Allergy Clin Immunol, 131, 541-548 e9.

SIRAGANIAN, R. P. 2003. Mast cell signal transduction from the high-affinity IgE receptor. Curr Opin Immunol, 15, 639-46.

SUZUKI, K. G., FUJIWARA, T. K., SANEMATSU, F., IINO, R., EDIDIN, M. \& KUSUMI, A. 2007. GPIanchored receptor clusters transiently recruit Lyn and $G$ alpha for temporary cluster immobilization and Lyn activation: single-molecule tracking study 1. J Cell Biol, 177, 717-30.

VEILLETTE, A. 2010. SLAM-family receptors: immune regulators with or without SAP-family adaptors. Cold Spring Harb Perspect Biol, 2, a002469.

\section{Cross-references}

Allergen Immunotherapy:Mechanisms of IT Essay 00527 29/29

Autoimmune disease Essay 00203 59/59

Chemokines Essay 00034 91/91

FcRIIb Essay 00205 159/159

IgE receptor Essay 00075 185/185

Leukotriene receptor antagonists Essay 00241 225/225

mAbs (omalizumab) Essay 00249 232/232

Mast cell growth and development Essay 00083 235/235

Mast cell-derived mediators Essay 00093 236/236

Mastocytosis Essay 00095 237/237

Role of IgE in disease Essay 00079 319/319

Role of mast cells in disease Essay 00094 320/320

SHIP Essay 00047 327/327

Specific IgE Essay 00077 347/347

TGFbeta Essay $00021364 / 364$ 
Table 1: Activating receptors expressed by mast cells.

\begin{tabular}{|c|c|c|c|c|c|}
\hline \multirow{2}{*}{ Ligands } & \multicolumn{5}{|c|}{ Activating Receptors } \\
\hline & $\begin{array}{ll} & \text { IgSF } \\
\text { RTK Immunoreceptors }\end{array}$ & $\begin{array}{l}\text { 7TM } \\
\text { GPCR }\end{array}$ & $\begin{array}{l}\text { Cytokine } \\
\text { Receptors }\end{array}$ & $\begin{array}{l}\text { Toll-Llke } \\
\text { Receptors }\end{array}$ & $\begin{array}{l}\text { GPI-anch. } \\
\text { Receptors }\end{array}$ \\
\hline $\begin{array}{l}\text { Growth } \\
\text { Factors } \\
\text { Antibodies }\end{array}$ & 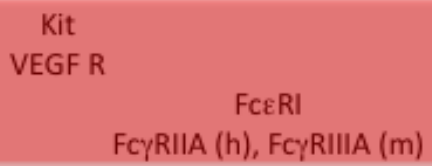 & & & & \\
\hline Chemokines & & $\begin{array}{l}\text { CXCR1-4 } \\
\text { CX3CR1 } \\
\text { CCR3-5 } \\
\text { CCR1 }\end{array}$ & & & \\
\hline Lipid Mediators & & $\begin{array}{l}\text { LT R } \\
\text { PAF R } \\
\text { EP3 }\end{array}$ & & & \\
\hline $\begin{array}{lr}\text { Amines } & \begin{array}{r}\text { Histamine } \\
\text { Serotonin }\end{array} \\
\text { Sphingosine P } & \\
\text { Adenosine } & \end{array}$ & & $\begin{array}{l}\text { H1-4R } \\
\text { 5HTR } \\
\text { S1P-R1/2 } \\
\text { A1, A3 }\end{array}$ & & & \\
\hline $\begin{array}{lr}\text { Neuropeptides } & \text { Subst. P } \\
\text { Anaphylatoxins } & \text { C3a/C5a } \\
\text { Leucotrienes } & \\
\text { Endothelins } & \text { ET-1-3 } \\
\text { Corticotropin } & \text { CRF }\end{array}$ & & $\begin{array}{c}\text { NK1R } \\
\text { C3a R/C5a R } \\
\text { CysLT1 } / 2 \\
\text { ETA, ETB } \\
\text { CRH R }\end{array}$ & & & \\
\hline $\begin{array}{l}I L-3-5 \\
T S L P\end{array}$ & & & $\begin{array}{c}\text { IL-3 R } \\
\text { IL-4 R } \\
\text { IL-5 R } \\
\text { TSLP R/IL-7 R }\end{array}$ & & \\
\hline $\begin{array}{r}\text { Microb. Prod. } \begin{array}{r}\text { endotoxins } \\
\text { UPA }\end{array} \\
\text { Bacteria, 2B4 }\end{array}$ & & & & TLR2 /TLR4 & $\begin{array}{l}\text { UPA R } \\
\text { CD48 }\end{array}$ \\
\hline
\end{tabular}


Table 2: Inhibitory receptors expressed by mast cells.

\begin{tabular}{|c|c|c|c|}
\hline \multirow[b]{2}{*}{ Ligands } & \multicolumn{2}{|c|}{ ITIM-containing Receptors } & \multirow[t]{2}{*}{ Non ITIM } \\
\hline & $S H I P 1 / 2$ & SHP-1/2 & \\
\hline IgG immune complexes & Fc $\gamma R \| B$ & & \\
\hline Sialic acid & & Siglec & \\
\hline Ph.serine/ethanolamine; ceramides & & MAIR-I (CD300) & \\
\hline$C D 47$ & & SIRPa & \\
\hline$M H C-I$ & & PIRB & \\
\hline$M H C-I(H L A-G)$ & & ILT/LIRs & \\
\hline$M H C-I(H L A-E)$ & & NKG2A (CD94) & \\
\hline PECAM-1 & & PECAM-1 & \\
\hline Collagen & & LAIR-1 (CD305) & \\
\hline CD5 & & CD72 & \\
\hline integrin $\alpha(v) \beta 3$ & & gp49B1 & \\
\hline ? & & Allergin-1 & \\
\hline Microbial products & & & TLR4 \\
\hline$O X-2$ & & & CD200R1 \\
\hline TGFB & & & TGF $\beta-R 1$ \\
\hline PGE2 & & & EP2 \\
\hline Adenosine & & & $\mathrm{A} 2 \mathrm{a}, \mathrm{A} 2 \mathrm{~b}$ \\
\hline IL-10 & & & IL-10R \\
\hline IL-33 & & & ST2/IL1RL1 \\
\hline
\end{tabular}

